\title{
Retraction Note to: Effect of Zn substitution on the structural, magnetic, optical, and electrical properties of low-temperature-synthesized cobalt ferrites
}

\author{
Muhammad Sajjad ${ }^{1}$, Khuram Ali ${ }^{1, \star}$ (1), Yasir Jamil ${ }^{1}$, Saira Sehar ${ }^{1}$, Lubna Akbar ${ }^{1}$, \\ Muhammad Tahir ${ }^{1}$, and Meshal Alzaid ${ }^{2}$ \\ ${ }^{1}$ Nano-Optoelectronics Research Laboratory, Department of Physics, University of Agriculture Faisalabad, Faisalabad 38040, \\ Pakistan \\ ${ }^{2}$ Physics Department, College of Science, Jouf University, P.O. Box 2014, Al-Jouf, Sakaka, Saudi Arabia
}

Published online:

9 October 2021

(C) Springer Science+Business Media, LLC, part of Springer

Nature 2021
Retraction to: Journal of Materials Science:

Materials in Electronics (2021) 32:6001-6013

https://doi.org/10.1007/s10854-021-05320-y

The Editor-in-Chief has retracted this article. Concerns were raised regarding Fig. 2, specifically all five XRD plots appear to be identical, despite representing compounds with different levels of zinc. The
Editor-in-Chief therefore no longer has confidence in the reliability of the data reported in the article. The authors have not responded to correspondence regarding this retraction.

Publisher's Note Springer Nature remains neutral with regard to jurisdictional claims in published maps and institutional affiliations.

The original article can be found online at https:/ / doi.org/10.1007/s10854-021-05320-y.

Address correspondence to E-mail: khuram_uaf@yahoo.com 